\title{
ANÁLISE DOGMÁTICA SOBRE OS WEBSITES DE PROMOÇÃO DA PROSTITUIÇÃO: Da Legalidade e Respectiva Responsabilidade Penal dos Webmasters
}

DOGMATIC ANALYSIS ABOUT THE PROMOTION OF WEBSITES OF PROSTITUTION: Legality and the Criminal Liability for Their Webmasters

Rodrigo de Almeida Leite * Mateus Ferreira Nobre**

Data de recebimento: $12 / 02 / 2015$ Data da aprovação: 10/06/2015

\section{RESUMO}

O presente artigo objetiva analisar o fenômeno dos websites de promoção de prostituição, classificando-os, e definir sua legalidade em cada tipo verificando o envolvimento com práticas de exploração sexual. Além da tipificação e análise de legalidade, este artigo tratará da definição da responsabilidade penal dos seus respectivos webmasters, baseado no respectivo envolvimento com os esquemas de exploração sexual, correlacionando com as tipificações de websites descritas.

* Especialista em Direito e Políticas da União Europeia pela Universidade de Salamanca. Mestre em Direito pela Universidade Clássica de Lisboa.

Doutorando em Ciência Política pela Universidade Federal de Pernambuco (UFPE). Professor do Curso de Direito da UFERSA.

Membro do Núcleo de Direito Cibernético (NUDIC-UFERSA).

E-mail: roalmleite@gmail.com

** Graduando do Curso de Direito da Universidade Federal Rural do

Semi-Árido (UFERSA). Membro do Núcleo de Direito Cibernético

(NUDIC-UFERSA). Conselheiro Fiscal da Wikimedia Brasil.

E-mail: mateusfnobre@gmail.com 


\title{
PALAVRAS-CHAVE
}

Sites de exploração sexual; Prostituição; Responsabilidade penal; Webmaster.

\begin{abstract}
This article objectifies to analyze the phenomenon of the prostitution's promotion websites, by classifying them, and define them legality in each type by verifying each involvement with sexual exploitation practices. Further than typifying and analyze legality, this article will treat the definition of criminal liability of their respective webmasters, based in them respective involvement with the broader sexual exploitation mafia, correlating with the already described websites typifications.
\end{abstract}

\section{KEY WORDS}

Sexual exploitation sites; Prostitution; Criminal liability; Webmasters. 


\section{INTRODUÇÃO}

A internet, como uma nova mídia, traz meios alternativos de representar crimes, novas maneiras de praticar velhos delitos. E os crimes relacionados à prostituição não são exceção. Entretanto, nem todo website relacionado à prostituição na internet pode ser criminalizado. A situação de novidade e a característica propriamente líquida, contemporânea da internet, é passível de trazer nebulosidade e confusão para os magistrados, dificultando o processo de subsunção. São complexidades típicas de uma situação nova.

Se nas máfias de exploração sexual clássicas, sem envolvimento com a internet, o "cafetão" era a figura central, no contexto contemporâneo-virtual o ator principal passa a ser o webmaster. Esta contemporânea figura caracteriza-se por pessoa capaz e responsável pela criação e postagem de um website na rede, sendo o criador e gerenciador da tecnologia, da estrutura e de todo o conteúdo do site (SEBELY, 2001). Logo, no contexto dos websites de promoção de prostituição, são eles os criadores, e talvez também os administradores, dos respectivos domínios. Desta forma, nos novos meios de exploração sexual, o webmaster passa a ser figura de relevante importância, por sua necessidade na administração.

Neste sentido, o trabalho ora proposto possui dois objetivos: a) classificar os tipos de websites de promoção da prostituição, diferenciando os tipos legais dos tipos ilegais, utilizando de analogias com as situações já familiares no âmbito da prostituição e exploração sexual, e 2) determinar e corresponder as respectivas punibilidades dos webmasters criadores e/ou administradores dos websites que promovem exploração sexual.

As conceituações aqui elaboradas foram fruto de pesquisa bibliográfica e jurisprudencial sobre o tema, além de observação na internet sobre sites de exploração sexual e notícias sobre o tema veiculadas nos meios de comunicação.

\section{A EXPLORAÇÃO SEXUAL E SEUS DERIVATIVOS PENAIS}

Como tarefa inicial neste artigo, abordaremos o conceito da exploração sexual, uma vez que trataremos de crimes relacionados necessariamente a este tipo.

A exploração sexual, embora citada como condição por quatro vezes no capítulo do código penal, dentro dos artigos que tratam dos crimes relacionados, não encontra conceito bem definido e sedimentado no âmbito dogmático e doutrinário.

Já houve uma tentativa de definir a exploração sexual legislativamente, 
mas que não logrou êxito. Esta falha simplesmente ocorreu pela imprecisão de tal conceito. Assim, apesar das reiteradas citações no código penal (inclusive como condição essencial para perfazimento do crime - vide Capítulo V do Código Penal), os operadores do direito têm que se satisfazer com uma vaga ideia do que seja a exploração sexual, ou as contraditórias concepções doutrinárias.

Alguns doutrinadores, como Prado (2008, p. 708), trazem o conceito de exploração sexual como a "utilização de uma pessoa para fins sexuais, com ânimo de lucro, atentando direta ou indiretamente contra sua dignidade e liberdade sexual, e afetando potencialmente seu equilíbrio psicosocial".

Desta forma, o conceito de exploração sexual prende-se ao "ânimo de lucro". Entretanto, Ferreira (2009) controverte tal conceito com acertadas possibilidades fáticas:

Esse proveito, segundo pensamos, pode ser de ordem econômica ou não. Se for de ordem econômica, fala-se em exploração sexual comercial. Resta, ainda, definir se em todo favorecimento à exploração sexual exige-se que haja intenção do agente de submeter a vítima a uma atividade habitual como é a prostituição. Aresposta a tal assertiva nos parece que seja negativa, sob de pena de confundirmos o conceito amplo de exploração sexual com o conceito de prostituição. Desse modo, entendemos que, por exemplo, o pai que, almejando ser promovido, induz sua filha maior de idade a satisfazer a lascívia dos seus superiores para que estes lhe concedam uma promoção, incorre no crime do art. $228, \S 1^{\circ}$, do CP, por estar submetendo-a a exploração sexual. Do mesmo modo o advogado, também a título de exemplo, que induz sua assistente a prestar favores sexuais a autoridades em troca de posicionamentos favoráveis nas demandas que patrocina, pela linha de raciocínio ora defendida, está submetendo-a a exploração sexual (FERREIRA, 2009).

Ao analisar ambos os posicionamentos, consideramos mais adequada a concepção de Ferreira (2009), na qual exploração sexual figura como tirar proveito da atividade sexual alheia. Este proveito pode ser de ordem econômica ou não, como aqui demonstrado. Nestes termos, a prostituição em si é uma profissão autônoma como qualquer outra, não-criminalizada. A prostituição apenas se torna crime dentro do contexto da exploração sexual, sendo utilizada sua atividade para proveito alheio além do proveito pessoal. Nucci (2012, p. 1001) inclusive chega a conceituar que "a exploração sexual é o gênero do qual se extrai a prostituição".

Definida a exploração sexual, abordemos os derivativos penais desta no código penal vernáculo hodierno. $\mathrm{O}$ capítulo $\mathrm{V}$ do código penal tem como título 
"Do lenocínio e do tráfico de pessoa para fim de prostituição ou outra forma de exploração sexual". Compreende o trecho do artigo 227 ao artigo 232. Alguns deles já foram vetados. Basicamente, trata de assuntos como: lenocínio, favorecimento à prostituição, estabelecimentos físicos de exploração sexual, rufianismo e tráfico interno e externo com fins de prostituição. No presente artigo, contudo, trataremos especificamente de três artigos.

O primeiro deles refere-se ao favorecimento da prostituição ou outra forma de exploração sexual, tipificado no art. 228 do Código Penal:

Art. 228. Induzir ou atrair alguém à prostituição ou outra forma de exploração sexual, facilitá-la, impedir ou dificultar que alguém a abandone: [...]

$\S 3^{\circ}$ - Se o crime é cometido com o fim de lucro, aplica-se também multa.

Em relação ao assunto aqui tratado, o trecho que será reiterado é o "facilitála". Faremos a exegese inicialmente, visto que retornaremos a este detalhe várias vezes durante o artigo.

Sobre o tema, Greco (2009, p. 573) doutrina que se consuma o crime com qualquer ato que colabore para que a vítima passe a ser sexualmente explorada. Jesus (2009, p. 155) exemplifica que qualquer ato que facilite a "angariação" de clientes para a vítima explorada sexualmente, consumará o crime do artigo 228. Logo, se qualquer ato que aumente a chance da vítima ser explorada sexualmente possa ser considerado facilitação, por conseguinte qualquer forma de promoção/publicidade de atividade de exploração sexual será considerada "facilitação", e o(s) responsável(is) passível(is) de punição nos termos do artigo 228 do Código Penal. Se se promove exploração sexual, é facilitação. Quem trata de promoção, trata de facilitação.

Verifica-se também que se alguém pratica a facilitação com fim de lucro, aplica-se multa, além da pena. Logo, se alguém se propõe a fazer publicidade de algum meio de exploração sexual por um pagamento (fixo ou único, uma "relação de emprego" informal ou uma prestação de serviço única), esta ação além de passível de prisão, também é passível de multa.

Dando continuidade aos crimes a serem analisados, trataremos sobre o crime de mantimento de Casa de Prostituição e Rufianismo, estabelecidos nos arts. 229 e 230 do Código Penal:

Casa de prostituição

Art. 229. Manter, por conta própria ou de terceiro, estabelecimento em que ocorra exploração sexual, haja, ou não, intuito de lucro ou mediação direta 
do proprietário ou gerente:

Pena - reclusão, de dois a cinco anos, e multa.

Rufianismo

Art. 230 - Tirar proveito da prostituição alheia, participando diretamente de seus lucros ou fazendo-se sustentar, no todo ou em parte, por quem a exerça:

Pena - reclusão, de um a quatro anos, e multa. [...]

Nota-se que não só aquele que obtém participação direta na arrecadação de prostituição alheia (o típico cafetão) é condenável por este artigo, mas também aqueles que se sustentam por quem a exerça. Ou seja, verifica-se que um possível empregado do cafetão, alguém que trabalhe fixamente em um ambiente de exploração sexual, recebendo um salário, também é passível de processo. Logo, não só o cafetão, mas todos que trabalham juntamente com esse são passíveis de tipificação, segundo o artigo 230.

\section{OS SITES DE PROMOÇÃO DA PROSTITUIÇÃO E SUA TIPIFICAÇÃO}

A internet, como uma nova mídia, trouxe meios alternativos de representação de crimes no gênero da exploração sexual. As pessoas utilizam a internet e nela injetam sua criatividade, e com o advento da contemporaneidade logo surgiram novos meios de representação de velhos crimes, como o favorecimento da prostituição e o rufianismo. Neste tópico dividiremos e tipificaremos os websites que promovem a prostituição e discutiremos sua respectiva (i)legalidade.

Uma pequena observação: já foi discutida a diferença entre a prostituição e a exploração sexual. A primeira, via de regra, não é criminalizada. A prostituição só é criminalizada quando se encontra no contexto da segunda (exploração sexual). Portanto, discutiremos se cada tipificação se encontra em um contexto de exploração sexual ou não, portanto, se é ilegal ou não.

\subsection{Sites de prostíbulos}

Assim como uma loja de eletrodomésticos pode ter um website expondo seus produtos, com os respectivos preços, telefone para contato e o endereço para possível visita, um proprietário de uma casa de prostituição também pode se interessar em criar um website para expor fotografias das profissionais que lá trabalham, seus 
respectivos preços por programa sexual, disponibilizar um telefone para contato e talvez o endereço para posteriores visitas dos apreciadores de prostíbulos. Porém, diferentemente do site da loja de eletrodomésticos, as casas de prostituição têm um objeto de "venda" ilícito. Um website deste tipo é reflexo de uma prática criminal.

Este tipo de website pode ser considerado simplesmente como um meio de promoção de um estabelecimento físico de exploração sexual. Assim sendo, um meio de facilitação da prostituição, proibido pelo artigo 228 do Código Penal. Consequentemente, o website de prostíbulo é um instrumento ilegal de publicidade.

\subsection{Agências virtuais rufianistas}

As agências rufianistas virtuais demonstram a liquidez e criatividade da modernidade. São websites que agem tal qual rufiões, tirando proveito da prostituição alheia, porém com toda a prática virtual, sem um local físico, apenas na internet.

Pode-se descrever estas agências exemplificando-as. Imagine um website no qual aparecem fotografias de diversas profissionais do sexo, e você é livre para navegar entre elas no site, verificando várias fotos de garotas distintas. Se o nosso navegante interessar-se no serviço de uma das garotas expostas, este navegante interessado liga para o número de telefone descrito no site. A pessoa que atende (neste caso, o rufião), serve como intermediário entre o navegante e a prostituta. Obviamente, este rufião tem a posse do contato do interessado, logo, tem o controle. Tendo o controle, este tira proveito direto da prostituição alheia. Ou a prostituta paga a percentagem acertada ao rufião virtual, ou perde o cliente.

Nesta tipificação de website de prostituição, é possível dissociar propriamente a prática do rufianismo de um estabelecimento físico. É possível ser um rufião sem ter um estabelecimento de meretrício, apenas tendo um "estabelecimento virtual".

Neste caso, o website incorreria como um meio facilitador da prostituição (art. 228, Código Penal) e como meio de exercer o rufianismo (art. 230, Código Penal). Consequentemente, verifica-se que tal tipo de mecanismo configura-se uma prática criminosa.

\subsection{Catálogos virtuais de prostituição}

O tipo aqui exposto funciona como verdadeiro catálogo do meretrício. Estes tipos de websites expõem fotografias e contatos de dezenas de profissionais do sexo. Muitas vezes, em sites de grandeza maior (magnitude de todo o território nacional), 
são divididas por estados e até cidades. Caso o navegante se interesse, esse consegue achar o contato direto da prostituta (telefone celular) em sua respectiva página.

Este tipo é diametralmente oposto ao tipo anterior descrito, agência rufianista virtual. Nos catálogos da prostituição não há intermediário. A meretriz é contatada diretamente em telefone celular próprio. Uma vez que não há intermediário, não há modo de tirar proveito da prostituição alheia, participando diretamente de seus lucros ou fazendo sustentar, no todo ou em parte, por quem a exerça. Não há crime de rufianismo.

Aliás, o catálogo virtual de prostituição da contemporaneidade em muito se assemelha com uma manifestação da prostituição tradicional de décadas: a seção adulta dos classificados do jornal.

Ora, na seção adulta encontramos numerosos anúncios de profissionais do sexo, com seus respectivos números pessoais, e é sabido que os jornais não são passíveis de processo por alguma forma de promoção ou proveito sobre exploração sexual. Isto é porque tanto os classificados do jornal quanto os catálogos virtuais da prostituição não tiram proveito da prostituição alheia, participando diretamente do lucro, e sim cobram um determinado valor pela exposição (com fins publicitários e pessoais), que não é uma participação direta nos programas do(a) profissional do sexo. $\mathrm{O}$ valor para ser exposto tanto em um classificado quanto no catálogo virtual da prostituição não é de qualquer forma um modo de exploração sexual, visto que não é uma participação, não é proporcional e só é pago uma vez (por anúncio). Não tem qualquer relação com os ganhos da prostituta. Os catálogos virtuais da prostituição não representam qualquer forma de crime de exploração sexual, são apenas um meio de realizar marketing sobre o trabalho de profissionais do sexo autônomas.

Sobre o tema, Nucci $(2012$, p. 997) relata com lucidez este tipo de promoção pessoal, ressaltando que "se tal conduta fosse realmente relevante e danosa à sociedade, não se teria a proliferação de anúncios e propagandas de toda ordem nessa área, com o beneplácito das autoridades".Dessa forma, verifica-se que o tipo catálogo virtual da prostituição é legal, e seus respectivos webmasters não devem ser passíveis de qualquer processo penal.

\section{DA RESPONSABILIDADE PENAL DO WEBMASTER NOS TIPOS ILEGAIS}

Desvendamos que, das três tipificações nas quais dividimos os websites de promoção de prostituição (sites de prostíbulos, agências virtuais rufianistas, catálogos 
da prostituição virtuais), dois deles são correlacionados com práticas de exploração sexual (sites de prostíbulos e agências virtuais rufianistas) e, por conseguinte, ilegais e passíveis de responsabilização de seus webmasters. Logo, focaremos a continuação desta pesquisa na responsabilidade dos webmasters, relacionando com as tipificações do site e as possibilidades de envolvimento do webmaster com o projeto maior.

Investigaremos a responsabilidade penal dos webmasters pondo uma linha mestra inicial: 1) quando o webmaster coincide com o proprietário; e 2) quando o webmaster difere do proprietário. Na primeira possibilidade, quando o webmaster e o proprietário da máfia de exploração sexual são a mesma pessoa, subdividimos, a partir da tipificação já analisada, em: 1.1) se se trata de um site de prostíbulo; e 1.2) se agência virtual rufianista.

Caso a segunda possibilidade seja real, quando o chefe da máfia de exploração sexual e o webmaster não são a mesma pessoa, subdivimos a partir de critério de envolvimento: 2.1) quando o webmaster for integrante fixo; e 2.2) quando for terceiro prestador de serviço. Nesta lógica, abordaremos todos os casos possíveis de responsabilidade do webmaster.

\subsection{Quando o webmaster coincide com o proprietário}

Utilizamos o termo "proprietário" não como o proprietário civil do estabelecimento onde ocorre exploração sexual. Utilizamos proprietário em consonância com o mantenedor, descrito e exposto no artigo 228 do Código Penal, em "manter, por conta própria ou de terceiro, estabelecimento em que ocorra exploração sexual, haja, ou não, intuito de lucro ou mediação direta do proprietário ou gerente". Logo, o proprietário pode ser meramente a pessoa que administra o estabelecimento - o próprio proprietário civil ou não. Entretanto, já vimos aqui que neste contexto contemporâneo o estabelecimento físico não é de todo indispensável, quebrando paradigmas. Então, em última instância, conceituamos proprietário como a pessoa que tem domínio do fato (chefe ou administrador) sobre a máfia de exploração sexual do caso em questão. Onde se lê "proprietário", leia-se "chefe ou administrador do esquema".

\subsubsection{Quando existe um site de prostíbulo}

A situação aqui analisada é a de um proprietário de uma casa de prostituição física - tal como prevista no artigo 229 do Código Penal - que, buscando uma promoção, uma facilitação de sua atividade rufianista (tal como prevista no artigo 230), produz por conta própria um website para publicidade de seu recinto do mere- 
trício. A figura do proprietário e do webmaster coincidem.

Logo, conclui-se que o proprietário aqui investigado seria responsável por três crimes. O previsto no artigo 228 - por ter criado um website para a facilitação da prostituição que "administrava" -, o do artigo 229 - por manter estabelecimento no qual ocorre exploração sexual -, e do artigo 230 - por tirar proveito direto de exploração sexual, sendo rufião.

Sendo os crimes expostos praticados em concurso material pela pluralidade de ações, as penas se aplicam cumulativamente, configurando concurso material.

Alguma jurisprudência recente vem apontando penas para crimes com resultados tais quais esses, e que o crime previsto no artigo 230 absorve o crime (i.e., a pena) previsto no artigo 228. Isto é tanto teoricamente quanto praticamente inaceitável. O artigo 230 nunca pode absorver o crime do artigo 228. Com toda venialidade - sendo a pena do artigo 230 maior que a do 228 - um crime de menor pena não poderia absorver um de pena maior. Permitir tal hermenêutica traria consequências insólitas e danosas para a sociedade. Seria admitir que um crime de menor impacto, em circunstâncias favoráveis, pode absorver um de maior impacto.

Por exemplo, um infrator, em concurso, ter seu crime de pena máxima de dois anos absorvendo outro crime - em circunstâncias favoráveis - de pena máxima de oito anos. Desta forma, repudiamos teórica e pragmaticamente esta posição, em que se encontra grosseiro erro jurídico.

Sabendo disto, somando as penas dos três crimes no qual o webmasterproprietário se responsabilizaria no caso aqui investigado, cumulativamente, esse seria passível de uma condenação base de 5 a 14 anos.

\subsubsection{A situação em uma agência rufianista virtual}

A situação aqui analisada é a de um fundador de uma agência rufianista virtual que também é seu webmaster. Visto que o fundador de uma agência virtual rufianista é tipicamente o cafetão - participa diretamente dos lucros de prostituição alheia - a figura do rufião (artigo 230) e a do webmaster que promove a prostituição (artigo 228) coincidem numa mesma pessoa física.

Pela própria natureza da agência rufianista virtual (como descrita no subtópico 2.2), ocorre rufianismo e facilitação de prostituição simultaneamente e sem um estabelecimento físico. Também, por esta mesma natureza, a facilitação da prostituição e a própria prática do rufianismo se efetivam numa mesma conduta, na criação do website que será a agência rufianista virtual. E quando dois ou mais crimes se efetivam em uma conduta singular e una caracteriza-se um concurso formal. 
A lei e a doutrina diferenciam o concurso formal em dois critérios: homogeneidade e perfeição. A homogeneidade ocorre quando os dois (ou mais) crimes cometidos são iguais. Caso não, o concurso é heterogêneo. A perfeição ocorre quando no mínimo um dos crimes ocorre culposamente. Quando não (todos os crimes são cometidos com algum tipo de dolo), o concurso é imperfeito (GERLACK NETO, 2007, p. 32). Estes critérios criam quatro tipos quando se correlacionam: homogêneo perfeito, heterogêneo perfeito, homogêneo imperfeito, heterogêneo imperfeito.

Não mais nos alongando sobre esta questão, verificamos que o concurso formal da situação aqui descrita é um concurso formal heterogêneo imperfeito. Heterogêneo pois os crimes são diferentes (artigo 228 e 230 do código penal).

E visto que caracterizar o concurso formal como imperfeito causa aumento significativo na pena, nos permitimos nos alongar um pouco mais nesse ponto para prová-lo, a fim de não fazer qualquer webmaster passar mais tempo do que o justo na prisão.

Sobre concurso formal imperfeito, nos ensina Capez (2003, p. 459):

O desígnio autônomo ou a pluralidade de desígnios indica a intenção do sujeito (dolo direto) ou a assunção do risco pelo sujeito (dolo eventual) de, com uma única conduta, produzir dois ou mais resultados criminosos (dois ou mais delitos). Note, portanto, que o concurso formal perfeito pode ocorrer entre dois crimes culposos ou um doloso e outro culposo, ao passo que o concurso formal imperfeito fica restrito aos crimes dolosos.

Na situação aqui analisada, nenhum dos dois crimes cometidos é culposo. $\mathrm{O}$ webmaster tanto deseja praticar o rufianismo quanto deseja promover seu rufianismo. Os desígnios não são únicos, são plurais. Nenhum dos crimes - tanto o rufianismo quanto a facilitação - ocorre por acidente, culposamente. O autor deseja os dois, e mesmo com a unicidade de conduta, há a pluralidade volitiva. Caracteriza-se concurso formal imperfeito. E segundo o artigo 70 do nosso CódigoPenal, "as penas aplicam-se, entretanto, cumulativamente, se a ação ou omissão é dolosa e os crimes concorrentes resultam de desígnios autônomos, consoante o disposto no artigo anterior".

Assim sendo, cabe-se cumulação das penas. Adicionando as penas bases dos crimes previstos no artigo 228 e 230, o webmaster-proprietário deste caso estudado seria cabível de receber, como pena base, de 3 a 9 anos de prisão.

\subsection{Quando o webmaster difere do proprietário}

Tipificamos as possibilidades de quando o webmaster difere do proprietário 
em duas: quando integrante fixo (trabalha constantemente com os integrantes da exploração sexual e recebeu recursos reiteradas vezes proveito por isso) e quando terceiro prestador de serviço (prestou o serviço de criação de site e recebeu com isso apenas uma vez, não tendo envolvimento constante com o esquema).

\subsubsection{Quando integrante fixo}

A situação aqui analisada é a de que o webmaster é alguém que trabalha diretamente no esquema de exploração sexual. Exemplifica-se como "webmaster em tempo integral do website", "técnico em tempo integral", ou qualquer cargo dentro do esquema que o faça envolvido integralmente e diretamente com toda a máfia de exploração sexual na qual trabalha. O integrante fixo também recebe ao menos parte de seu sustento e/ou reiterado proveito do esquema.

O webmaster integrante fixo é culpável de dois crimes. O primeiro é o previsto no artigo 228, por criar o website do prostíbulo ou da agência virtual rufianista, sendo o website uma forma de promoção, ou seja, facilitação da exploração sexual. O segundo é o previsto no artigo 230, por tirar proveito/fazerse sustentar total ou parcialmente pela prostituição alheia. É culpável de facilitação de prostituição e rufianismo.

Sendo o webmaster um integrante fixo, ele passa a figurar como um ator principal na máfia de exploração sexual, classificando-se como coautor, passível de pena integral. É um colaborador necessário, se tornando peça chave no esquema, não mais dispensável pelo mero fato de trabalhar fixamente nele.

Assim sendo, o webmaster integrante fixo é passível de receber, como pena base, de 3 a 9 anos de prisão.

\subsubsection{O webmaster sendo terceiro contratado}

A situação aqui analisada é a de que o proprietário, desejando um aumento de requisição de seus serviços - publicidade -, contrata um terceiro para criar um website para sua casa de prostituição ou agência rufianista virtual. Este terceiro presta apenas um serviço - criação de website - e não tem qualquer envolvimento fixo com o proprietário.

A primeira pergunta a se fazer é se este terceiro prestador de serviço é passível de responsabilização penal (qualquer tipo) ou não é.

O argumento possível para absolvição deste prestador de serviço é a utili- 
zação da teoria do risco permitido e risco proibido, utilizando a tradicional analogia da hesitação do padeiro em vender um pão, a saber que o comprador quer envenenálo (CARVALHO, 2011), ou do taxista que leva um passageiro que pretende assassinar uma pessoa. Ora, há uma diferença estrutural entre o padeiro que vende um pão que supostamente será envenenado e um webmaster que cria um site de facilitação de prostituição. No segundo caso não há "supostamente". No mesmo momento que o webmaster cria o website, eis simultaneamente o crime do artigo 228 do nosso Código Penal efetivado. A facilitação é atingida no mesmo momento que o prestador de serviço completa o trabalho para o qual foi contratado. Como pode haver questão de risco em um crime cuja efetivação é total? Não pode, logicamente, se tratar de questão de risco quando a participação do webmaster torna o risco existente, visto que este efetiva o crime plenamente com sua prestação de serviço.

Logo, conclui-se preliminarmente que o webmaster prestador de serviço neste caso não pode ser absolvido. Então, dentre as possibilidades de autoria e participação, qual seria a mais precisa para o webmaster aqui descrito? Vejamos.

Para o nosso critério de identificação de autoria e participação, utilizamos a teoria do domínio do fato, defendida pelo jurista alemão Hans Welzen, sendo a teoria mais moderna e aceita pelos doutrinadores hodiernos (GALVÃO, 2007, p. 429). Segundo esta teoria, autores não necessariamente precisam cometer o ato tipificado, e partícipes não necessariamente carecem de não o fazer. Na verdade, a teoria do domínio do fato se guia mais pela eficácia do controle da situação do que com o critério meramente objetivo de tipificação ou não da conduta. Adicionamos ainda, que a teoria do domínio do fato, ao sintetizar critérios objetivos e subjetivos, se torna a teoria mais correta e acertada para explicar a identificação da autoria e participação.

O autor, por sua vez, é aquele participante que tem domínio final do fato, o que consegue efetivar sua volição ilícita (WESSEL, 1976, p. 120), neste caso, o proprietário, que efetivou sua vontade de facilitação da exploração sexual. O proprietário, mandante e contratante é o autor e senhor do fato a partir do momento que sua vontade se confirma no fato (WELZEL, 2002, p. 145). Neste caso estudado em particular, no exato momento que o website é criado, realiza-se a facilitação, e o proprietário perfaz seu talante. Ele é o determinador de sua ocorrência, determina seu modo de realização, institui quando começar e inclusive pode interromper seu processo. A figura do proprietário se identifica com o autor.

Logo, se o autor é o dominador do fato, ao partícipe fica a figura de coadjuvante. O partícipe é figura coadjuvante, lateral, e apenas empresta colaboração em um acontecimento dirigido pelo autor. Nestes termos, a figura do webmaster 
prestador de serviço se identifica com o partícipe.

Dessa forma, consideramos que, em um procedimento de dosimetria da pena, o webmaster figuraria como partícipe. De acordo com a doutrina (JAPIASSÚ, 2012, p. 307), a possível pena de um partícipe é regulamentada pelo artigo $29, \S 1^{\circ}$., do Código Penal pátrio. Neste contexto, o webmaster prestador de serviço do caso aqui explorado - sendo site de casa de prostituição ou agência rufianista virtual poderia ser condenado pelo artigo 228 do Código Penal (dois a cinco anos), com o atenuante previsto no artigo 29: a redução de um sexto a um terço da pena.

\section{CONSIDERAÇÕES FINAIS}

Uma vez caracterizado o conceito de exploração sexual, conseguimos definir quais sites desta modalidade figurariam ilegais ou não. Prostíbulo ou site de prostíbulo, ambos têm o mesmo cerne fundamental da exploração sexual, e logo tais tipos subsumem-se no mesmo artigo. Apesar do aspecto inovador das novas representações do crime nas novas mídias, é possível subsumir as novas manifestações nas velhas formas. E com base na teoria do domínio do fato, verificamos que a figura contemporânea do webmaster é passível de responsabilização penal em todos os tipos ilegais. Tal responsabilização também se varia pelo espectro previsto de maior ou menor participação, que classificamos de acordo com o envolvimento no esquema de exploração sexual.

\section{REFERÊNCIAS}

CAPEZ, Fernando. Curso de Direito Penal: parte geral. v.1. São Paulo: Saraiva, 2013.

CARVALHO, M. T. R. Síntese da Teoria da Imputação Objetiva no Direito Penal. Conteúdo Jurídico, Brasília, fev. 2011. Disponivel em: <http://www.conteudojuridico.com.br/?coluna s\&colunista=18240_\&ver=862>. Acesso em: 15 abr. 2014.

FERREIRA, Gecivaldo Vasconcelos. Crimes sexuais. Breves considerações sobre os artigos 227 a 234-B do Código Penal, de acordo com a Lei $n^{\circ}$ 12.015/2009. Jus Navigandi, Teresina. ano 14, nº2256, set. 2009. Disponível em: <http://jus.com.br/revista/texto/13442/crimes- 
sexuais/1>. Acesso em: 16 abr. 2014.

GALVÃO, Fernando. Direito Penal: Parte Geral. Belo Horizonte: Del Rey, 2007.

GERLACK NETO, Martinho Otto. Dicionário Técnico Jurídico de Direito Penal e Processual Penal. Juvevê: Juruá Editora, 2007.

GRECO, Rogério. Direito Penal. Vol. 3. Brasília: Impetus, 2009.

JAPIASSÚ, Carlos; SOUZA, Artur. Curso de Direito Penal: Parte Geral. Vol. 1. Rio de Janeiro: Elsevier Brasil, 2012.

JESUS, Damásio De. Direito Penal: Parte Especial. Vol. 3. São Paulo: Saraiva, 2009.

NUCCI, Guilherme de Souza. Código Penal Comentado. 12. ed. São Paulo, Revista dos Tribunais, 2012.

PRADO, Luiz Regis. Curso de Direito Penal Brasileiro. Vol, 2. São Paulo: Revista dos Tribunais, 2008.

SEBELY, Mario Matías. Que és un webmaster: Utilizamos muy habitualmente la palabra webmaster, pero ¿sabemos bien lo que significa? Madrid: 2001. Disponível em: $<$ http://www. desarrolloweb.com/articulos/465.php>. Acesso em: 16 abr. 2014.

WELZEL, Hans. Derecho Penal Alemán. Santiago: Juridica de Chille, 2002.

WESSEL, Johannes. Direito Penal: Parte Geral. Porto Alegre: Sérgio A Fabris, 1976. 